NBSIR 78-892

\title{
THE TIME DOMAIN CHARACTERISTICS OF A TRAVELING-WAVE LINEAR ANTENNA WITH LNNEAR AND NON-LNEERR LOADS
}

Motohisa Kanda

Electromagnetic Fields Division National Engineering Laboratory National Bureau of Standards Boulder, Colorado 80303 

NBSIR 78-892

\section{THE TIME DOMAIN CHARACTERISTICS OF A TRAVELING-WAVE LINEAR ANTENNA WITH LINEAR AND NON-LINEAR LOADS}

Motohisa Kanda

Electromagnetic Fields Division

National Engineering Laboratory

National Bureau of Standards

Boulder, Colorado 80303

February 1979

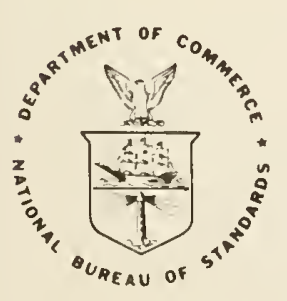

U.S. DEPARTMENT OF COMMERCE, Juanita M. Kreps, Secretary Sidney Harman, Under Secretary Jordan J. Baruch, Assistant Secretary for Science and Technology

NATIONAL BUREAU OF STANDARDS, Ernest Ambler, Director 



\section{CONTENTS}

Page

ABSTRACT---_-_-_-_-_-_-_- 1

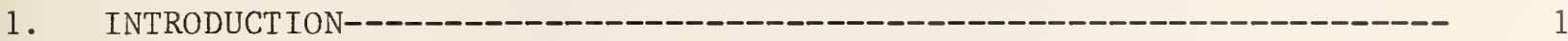

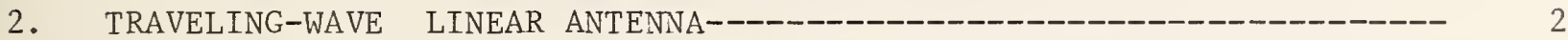

3. TRAVELING-WAVE LINEAR ANTENNA WITH A LINEAR LOAD----------------- 4

4. TRAVELING-WAVE LINEAR ANTENNA WITH A NONLINEAR LOAD----------------- 6

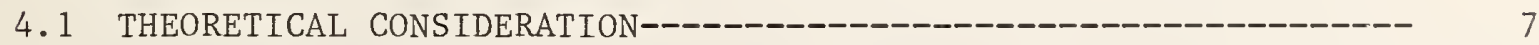

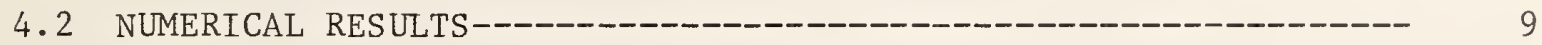

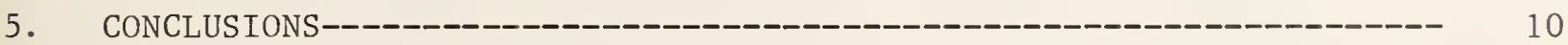

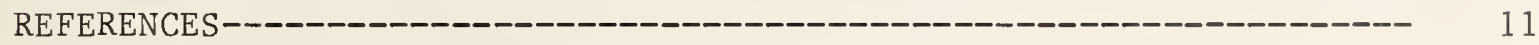



THE TIME-DOMAIN CHARACTERISTICS OF A TRAVELING-WAVE LINEAR ANTENNA WITH LINEAR AND NONLINEAR LOADS

\author{
Motohisa Kanda \\ Electromagnetic Fields Division \\ National Bureau of Standards \\ Boulder, Colorado 80303
}

This paper discusses the time-domain characteristics of a travelingwave linear antenna with linear and nonlinear loads. The fast Fourier transform (FFT) is used to analyze an antenna with a linear load. A numerical time-stepping, finite-difference equation method is used to analyze an antenna with a nonlinear load. The nonlinear effect is treated by the Newton-Raphson iteration technique. Effects of various linear and nonlinear loads are examined. Physical insight into the nonlinear loading of the antenna is also given in terms of detected time-domain sinusoidal electromagnetic (EM) waves.

Keywords: Fast Fourier transform; lewton-Raphson iteration method ; linear load; nonlinear load; time-domain measurements; time-stepping finitedifference technique; transient; traveling-wave antenna.

\title{
1. INTRODUCTION
}

It is well known that a conventional linear antenna, which supports an essentially standing-wave current distribution, is highly frequency sensitive because its antenna characteristics (e.g., current distribution, antenna admittance, radiation pattern, etc.) are strong functions of frequency. On the other hand, an essentially traveling-wave current distribution can be produced on a linear antenna by inserting a suitable loading resistor one-quarter wavelength from the end of the antenna, as indicated by Altshuler [1]. The correct value of loading resistance is not, however, easy to calculate since the antenna does not have a characteristic impedance analogous to TEM transmission line theory. Moreover, since the value and the location of the loading resistor are functions of frequency, this type of a linear antenna cannot be considered broadband.

Wu and King [2] demonstrated that a traveling-wave antenna can be realized by continuous resistive loading, where the internal impedance is a particular function of position along the antenna. Shen and Wu [3], Taylor [4], Shen [5], and Lally and Rouch [6] have modified and improved the original Wu-King theory and have done experimental work on a relatively long (more than $25 \mathrm{~cm}$ ) traveling-wave antenna. 
The author $[7,8]$ applied the method-of-monents technique to numerically solve the wave equation of a traveling-wave linear antenna. The current distribution, antenna admittance, near-field and far-field radiation patterns, and radiation efficiency of the antenna were calculated and compared with results calculated from Hu-King's current distribution. More recently, transients in traveling-wave linear antennas analyzed by the author $[9,10]$ have been compared with those in TEM horns and conical antennas.

In this paper, the time-domain characteristics of a traveling-wave linear antenna with linear and nonlinear loads are discussed. The characteristics of the antenna with a linear load are described first in the frequency domain. Various combinations of resistors and capacitors are used as linear loads. Very short, incident electromagnetic (EM) impulses of 100-ps duration and 1.5-ns duration are used for the analysis. Time-domain characteristics are then obtained using the fast Fourier transform (FFT) technique.

Traditionally, the characteristics of a linear antenna with a nonlinear load have been analyzed in the frequency domain by considering spectral components of solutions at harmonic frequencies [11]. For example, Sarker and Weiner [12] have used the Volterra series analysis to obtain the scattering of a nonlinearly loaded antenna. Calculation of the transfer fuction of a nonlinearly loaded antenna, however, becomes very tedious, particularly when circuit models for such a combination are very complicated. For this reason, recent analyses of nonlinearly loaded antennas have been evaluated using a direct time-domain technique $[13,14]$. In this paper, the time-domain characteristics of a traveling-wave linear antenna with a nonlinear load are derived by solving the time-domain, nonlinear equations using a time-stepping, finite-difference equation technique. The nonlinear effect is treated by the Newton-Raphson iteration method. The transfer function and the dynamic range of a traveling-wave antenna with a nonlinear load are derived. Physical insight into the nonlinear effects on an antenna is gained by an examination of the detected time-domain, sinusoidal EM waveforms.

\section{TRAVELING-HAVE LINEAR AIITENIIA}

In this paper, a traveling-wave linear antenna is realized by depositing a thin film of resistive material on a glass rod. The film thickness and, therefore, the resistance vary with position along the linear antenna. Although various types of resitive-loading profiles have been examined, the best are 
related to the Wu-king theory. That is, if the internal real impedance (i.e., resistance) per unit length $Z^{i}(z)$ as a function of the axial coordinate $z$ is given as

$$
z^{i}(z)=\frac{60|\Psi|}{h-|z|}
$$

then the current distribution $I_{Z}(z)$ along the linear antenna is that of a traveling wave; i.e.,

$$
I_{z}(z)=\frac{V_{0}}{60(1-j / k h)}\left[1-\frac{|z|}{h}\right] e^{-j k|z|} \text {. }
$$

The symbols have the following meanings: $h$ is half the physical length of the dipole, $k$ is the wave number, $V_{0}$ is the driving voltage, and $\Psi$ is given by

$$
\Psi=2\left[\sinh ^{-1} \frac{h}{a}-c(2 k a, 2 k h)-j S(2 k a, 2 k h)\right]+\frac{j}{k h}\left(1-e^{-j 2 k h}\right)
$$

where $a$ is the radius of the dipole, and $c(x, y)$ and $S(x, y)$ are the generalized cosine and sine integrals, respectively.

In recent work by the author $[7,8]$, current distributions on a travelingwave antenna are calculated by solving the one-dimensional wave equation numerically using the method of moments [15]. Figure 1 shows a traveling-wave linear antenna and its resistive-loading profile. Current distributions calculated from the method of moments and Wu-King's approximation are shown in figure 2 along with some experimental results. Theoretical and experimental results indicate that the current distribution along an antenna is indeed that of a traveling wave.

Once the current distribution on the traveling-wave antenna is given, the effective length and the driving-point impedance of the antenna can be determined. These quantities are needed for analyzing the time-domain characteristics of the antenna with linear and nonlinear loads. The effective length, $h_{e}(f)$, of the antenna is given by the moment of its current distribution, divided by the driving-point current; i.e.,

$$
h_{e}(f)=\frac{1}{I_{z}(0)} \int_{-h}^{h} I_{z}(z) d z .
$$


Using the approximate current distribution given in eq (2), the effective length $h_{e}(f)$ and the driving-point impedance $z_{0}(f)$ of the traveling-wave linear antenna are given by

$$
h_{e}(f)=\frac{2}{k^{2} h}\left(1-j k h-e^{-j k h}\right),
$$

and

$$
Z_{0}(f)=60 \Psi\left(1-\frac{j}{k h}\right)
$$

The effective length and the driving-point impedance of the antenna were also calculated using the current distribution obtained from the method of moments. The results are shown in figures 3 and 4 .

\section{TRAVELING-WAVE LINEAR ANTENNA WITH A LINEAR LOAD}

The characteristics of a traveling-wave linear antenna with a linear load are analyzed first in the frequency domain, and then the time-domain characteristics are obtained using the FFT.

Using the effective length $h_{e}(f)$ of the antenna, the open circuit voltage $V_{g}(f)$ of its equivalent source is given by

$$
V_{g}(f)=-h_{e}(f) E_{i n c}(f),
$$

where $E_{i n c}(f)$ is a normal incident electric field. The thevenin's equivalent circuit model for the antenna and a linear load is shown in figure 5. The receiving transfer function $S_{r}(f)$ of an antenna in the frequency domain is defined by

$$
S_{r}(f) \equiv \frac{V_{L}(f)}{E_{i n c}(f)}=\frac{-h_{e}(f) Z_{L}(f)}{Z_{0}(f)+Z_{L}(f)},
$$

where $V_{L}(f)$ is the induced voltage and $Z_{L}(f)$ is the load impedance of the antenna.

Figures $6 a$ and $6 b$ show the magnitude and phase of the transfer function of the traveling-wave antenna with various combinations of linear loads. The magnitude of the transfer function drops rapidly above $1 \mathrm{CHz}$ due to a rapid decrease in effective length as indicated in figure 3 . This rapid decrease in 
effective length above $1 \mathrm{CHz}$ prevents the antenna from resonating. Figure $6 \mathrm{a}$ shows that the magnitude of the transfer function of the antenna becomes constant with high impedance loads in the lower frequency range. Figure $6 \mathrm{~b}$ indicates that the total phase dispersion of the antenna up to $1 \mathrm{GHz}$ is still only $180^{\circ}$ for various linear loads, although a large phase degradation takes place above $100 \mathrm{MHz}$. This nondispersive characteristic is very useful for fast, time-varying, transient EM impulse measurements.

The time-domain characteristics of the traveling-wave linear antenna with a linear load were obtained using the FFT. Two incident FM impulses, one having a duration of about 100 ps and the other having a duration of $1.5 \mathrm{~ns}$, are used for time-domain analysis. The time-domain waveform and the amplitude spectra of an incident EM impulse with a 100-ps duration $(50 \%)$ are shown in figure 7 . The amplitude spectra are relatively flat up to $5 \mathrm{GHz}$. The time-domain EM impulse waveforms received by a traveling-wave antenna with various linear loads are shown in figures $8 \mathrm{a}$ and $8 \mathrm{~b}$. Figure $8 \mathrm{a}$ shows the EM impulse responses of an antenna with various resistive loads. Figure $8 \mathrm{~b}$ shows those with various capacitive loads and capacitive-resistive, parallel combination loads. For capacitive loads of $0.1 \mathrm{pF}$ and $1 \mathrm{pF}$, which represent typical capacitances of a sampler or of a high-frequency detection Schottky barrier diode, the resistive load predominantly determines the EM impulse waveforms, since the impedances corresponding to capacitances of $0.1 \mathrm{pF}$ and $1 \mathrm{pF}$ are very high. The lower the resistive load, the more predominant the down-shoot of the EM impulse waveforms becomes due to the low-frequency roll-off as shown in figure 6.

A 10 -frequency, incident EM Gaussian impulse with a duration of 1.5 ns was also used in the time-domain analysis. Its time-domain impulse waveform and amplitude spectra are shown in figure 9. The amplitude spectra are very flat to $200 \mathrm{MHz}$. The time-domain response of the traveling-wave antenna with various linear loads are shown in figures 10a, 10b, and 10c. Figures 10a, b, and $c$ show the time-domain responses of the antenna with various resistive, capacitive, and capacitive-resistive, parallel combination loads, respectively. The figures indicate that, as the loading impedance of the antenna decreases, the received time-doma in waveforms become time-differentiated and exhihit a predominant down-shoot. Thus, to reproduce the original incident EM impulse waveforms, a traveling-wave antenna should be terminated with a high, linear impedance load. 


\section{TRAVELIMC-WAVE LINEAR AIITENNA WITH A NOILIMEAR LOAD}

Thevenin's equivalent circuit models for the traveling-wave linear antenna with a nonlinear load are shown in figure 11. For both models in the figure, the traveling-wave linear antenna is modeled as an open circuit voltage source $\left|h_{e}\right| E_{i n c}$, and its driving-point impedance is represented by $R_{a}$ and $C_{a}$, in a series configuration. From the driving-point impedance given in figure $4, R_{a}$ is $250 \Omega$ and $C_{a}$ is $0.5 \mathrm{pF}$, for the purpose of the time-domain analysis of the models indicated in figure 11.

In Model I of figure 11, the characteristics of the traveling-wave linear antenna are determined by the nonlinear load, which is modeled with a nonlinear resistance $R_{n}$ and a linear capacitance $C_{d}$ in parallel configuration. In reality, a beam lead Schottky barrier diode, which is often used as a nonlinear load, is better represented by Model II shown in figure 11. Model II consists of a nonlinear resistance $R_{n}$ and a nonlinear junction capacitance $C_{j}$, as well as a linear series resistance $R_{S}$, linear package capacitance $C_{p}$, and lead inductance $L$.

The nonlinear resistance $R_{n}$ in Models $I$ and II can be described by the diode I-V characteristics, modeled as

$$
i=i_{s}\left(e^{\alpha V}-1\right)
$$

The symbols have the following meanings: $i$ is the current (amperes), $V$ is the voltage (volts) across the diode junction, is is the saturation current (amperes) which is assumed to be $2 \times 10^{-9} \mathrm{~A}$, and $\alpha \cong \mathrm{q} / \mathrm{nkT}=38 \mathrm{~V}-1$, where $q$ is the electronic charge $\left(1.6 \times 10^{-19}\right.$ coulomb), $n$ is the diode ideality factor $(\sim 1.05)$, $k$ is Boltzmann's constant $\left(1.38 \times 10^{-23} \mathrm{~J} / \mathrm{K}\right)$, and $T$ is the ambient temperature $(\sim 290 \mathrm{~K})$.

The nonlinear capacitance $C_{j}$ in Model II is represented by

$$
c_{j}(v)=\frac{c_{j}(0)}{\left(1-V / V_{b}\right)^{1 / 2}},
$$

where $C_{j}(0)$ is the zero bias function capacitance, typically $1 \mathrm{pF}$, and $V_{b}$ is the built-in potential, typically $0.45 \mathrm{eV}$ for the beam lead schottky barrier diode. 
The package linear capacitance $C_{p}$ in Model II is typically $0.1 \mathrm{pF}$. In Model I the nonlinear junction capacitance $C_{j}$ and the linear package capacitance $C_{p}$ are combined, where the total diode capacitance $C_{d}$ is assumed to be linear and to be $0.34 \mathrm{pF}$. The linear series resistance $R_{S}$ and the lead inductance $L$ in Model II are assumed to be, respectively, $8 \Omega$ and $0.1 \mathrm{nH}$. These elements are totally neglected in Model I.

\subsection{THEORETICAL CONSIDERATION}

The method used for analyzing time-domain characteristics of a travelingwave antenna with a nonlinear load is a time-stepping, finite-difference solution technique for obtaining the numerical solution to a time-domain model equation. The nonlinear effect caused by a nonlinear load is solved by the Newton-Raphson iteration method. The basic idea of the time-stepping, finite-difference equation technique is briefly discussed below. More detailed discussions on this subject are given by Calahan [16].

Linear and nonlinear elements are converted into a resistance-current equivalent network in the nodal equation method. For instance, in a regular $R$, $C$, and $L$ circuit, we have

$$
\begin{aligned}
V_{n} & =R i_{n}, \\
i_{n+1} & =C \frac{V_{n+1}-V_{n}}{\tau},
\end{aligned}
$$

and

$$
v_{n+1}=L \frac{i_{n+1}-i_{n}}{\tau}
$$

where $\tau$ is a sampling-time interval. Once the initial $V_{0}$ or $i_{0}$ is given, $V_{1}$ and $i_{1}$, then $V_{2}$ and $i_{2}$, etc. can be determined; such a method is, therefore, called a time-stepping, finite-difference equation method. 
In order to deal with nonlinear equations that result from nonlinear elements such as diodes, the Newton-Raphson iteration is used. The basic technique is discussed below. Given a nonlinear equation $f(i, v)$, the solution of $f(i, V)=0$ yields the solution of the nonlinear equation. First, $f(i, V)$ is expanded about an initial solution $\left[\begin{array}{ll}i & 0 \\ v & 0\end{array}\right]$; that is,

$$
f(i, V)=f\left(i^{0}, V^{0}\right)+J[f(i, V)]\left[\begin{array}{l}
\Delta i^{0} \\
\Delta V^{0}
\end{array}\right]
$$

where $J$ is the Jacobian of $f$ and has the form

$$
J=\left[\begin{array}{ccc}
\frac{\partial f_{1}}{\partial i_{1}} & \cdots & \frac{\partial f_{1}}{\partial V_{n+m}} \\
\vdots & & \vdots \\
\frac{\partial f_{n+m}^{\cdot}}{\partial i_{1}} & \cdots & \frac{\partial f_{n+m}}{\partial V_{n+m}}
\end{array}\right] .
$$

Now, $f(i, V)=0$ determines $\left[\begin{array}{l}\Delta i^{0} \\ \Delta V^{0}\end{array}\right]$ as

$$
J\left[f\left(i^{0}, v^{0}\right)\right]\left[\begin{array}{l}
\Delta i^{0} \\
\Delta v^{0}
\end{array}\right]=-f\left(i^{0}, v^{0}\right) \text {. }
$$

The solution $\left[\begin{array}{l}\Delta i^{0} \\ \Delta V^{0}\end{array}\right]$ updates the initial value of $\left[\begin{array}{l}\Delta i^{0} \\ \Delta V^{0}\end{array}\right]$, via

$$
\left[\begin{array}{l}
i^{n+1} \\
v^{n+1}
\end{array}\right]=\left[\begin{array}{c}
i^{n} \\
v^{n}
\end{array}\right]+\left[\begin{array}{c}
\Delta i^{n} \\
\Delta v^{n}
\end{array}\right] \text {. }
$$

The operation is repeated for $n=0,1,2, \ldots$, until the change $\left[\begin{array}{l}\Delta i \\ \Delta V\end{array}\right]$ is significantly small. 


\subsection{NUMERICAL RESULTS}

An incident, EM sinusoidal wave was used to examine the time-domain characteristics of a traveling-wave linear antenna with a nonlinear load. In the analysis, a single time-domain, sinusoidal EM wave was divided into 16 discrete digitized points (17 points including both ends). To arrive at the detected time-averaging of the sinusoidal wave excitation, 400 sinusoidal waves, which correspond to 6400 discrete points ( 16 points per cycle), were applied successively to a traveling-wave linear antenna with a nonlinear load to compute 6400 discrete induced voltages at the antenna terminal. These 6400 discrete voltages were then numerically averaged to arrive at the detected time-average of the sinusoidal EM wave excitation.

Figure 12 shows the detected 1st and 400th sinusoidal waves using Models I and II. Because of the nonlinear element, the detected sinusoidal wave is clearly skewed, and there is more negative than positive charge accumulation. Figure 13 shows the time-averaged, detected $d c$ induced voltage at the antenna terminals as a function of normal incident sinusoidal EM field. The experiments were performed using the traveling-wave linear antenna with a beam lead Schottky barrier diode as a nonlinear load, and the results are shown in this figure. From the theoretical and experimental results given in the figure, the detected dc voltage is shown to be precisely equal to the square of an incident EM field below a detected dc voltage of about 0.1 volt (square-law detection). Above a detected dc voltage of about 1 volt, the detected dc voltage is precisely proportional to an incident Ell field (1inear detection).

Figure 14 shows the transfer function of the traveling-wave antenna with a nonlinear load as a function of frequency. The transfer function of an antenna is defined in eq (8), with $E_{i n c}$ of $1 \mathrm{~V} / \mathrm{m}$. The theory and experimental results are in general agreement. The discrepancy between the theoretical and experimental results below $100 \mathrm{KHz}$ is mainly due to the effect of the resistive leads used as a dc pick-up in the experiments. The very sharp cut-off indicated below $100 \mathrm{KHz}$ and above $1 \mathrm{GHz}$ can be easily explained as follows. Figure 15 shows the detected time-domain EM sinusoidal waves at various frequencies. This figure shows clearly that the detected sinusoidal waves are more skewed and distorted at $10 \mathrm{MHz}$ than those at $10 \mathrm{kHz}$ and at $10 \mathrm{GHz}$. In turn, this skewed and distorted sinusoidal voltaģe causes more negative charge accumulation, leading to a very high detection efficiency. On the other hand, the smaller 
skeweness and distortion at $10 \mathrm{kHz}$ and $10 \mathrm{GHz}$, cancel positive and negative charge, and the net charge accumulation is almost zero, leading to a very low-detection efficiency.

\section{CONCLUSIONS}

This paper discussed the time-domain characteristics of a traveling-wave linear antenna with linear and nonlinear loads. The theoretical technique used for analyzing the time-domain characteristics of an antenna with a linear load is the FFT technique. Very fast impulses with durations of 100 ps and $1.5 \mathrm{~ns}$ were used in the analysis. Various combinations of resistances and capacitances were used as linear loads. In general, the traveling-wave linear antenna with a high impedance load preserves incident time-domain, transient EM waveforms. On the other hand, an antenna with a low impedance load causes time differentiation in the time-domain waveform due to a low-frequency roll-off in its transfer function.

The theoretical technique used for analyzing a traveling-wave antenna with a nonlinear load is the time-stepping, finite-difference equation method with the llewton-Raphson technique. Differential equations are solved using the time-stepping, finite-difference equation method, whereas the nonlinear effect is treated by the lewton-Raphson iteration technique. The dynamic range and the transfer function of the traveling-wave antenna with a beam lead Schottky barrier diode used as a nonlinear load were evaluated. The physical insight into the nonlinear response of the antenna can be gained by a qualitative discussion of the effects of skewness and distortion of detected time-domain EM waves. 
[1] Altshuler, E. E., The traveling-wave linear antenna, IEEE Trans. Antennas Propagat. AP-9, No. 4, 324-329 (July 1961).

[2] Wu, T. T., and King, R. W. P., The cylindrical antenna with nonreflecting resistive loading, IEEE Trans. Antennas Propagat. AP-13, No. 3, 369-373 (May 1965).

[3] Shen, L. C., and Wu, T. T., Cylindrical antenna with tapered resistive loading, Radio Science 2 , No. 2, 191-201 (Feb. 1967).

[4] Taylor, C. D., Cylindrical transmitting antenna: Tapered resistivity and multiple impedance loading, IEEE Trans. Antennas Propagat. AP-16, No. 2, 176-179 (March 1968).

[5] Shen, L. C., An experimental study of the antenna with nonreflecting resistive loading, IEEE Trans. Antennas Propagat. AP-15, No. 5, 606-611 (Sept. 1967).

[6] Lally, J. F., and Rouch, D. T., Experimental investigation of the broadband properties of a continuousiy loaded resistive monopole, IEEE Trans. Antennas Propagat. AP-18, No. 6, 764-768 (Nov. 1970).

[7] Kanda, M., The characteristics of a relatively short broadband linear antenna with tapered resistive loading, International Symposium on Antennas and Propagation, Digest, 230-233, Stanford Univ., CA (June 1977).

[8] Kanda, M., A relatively short cylindrical broadband antenna with tapered resistive loading for picosecond pulse measurement, IEEE Trans. Antennas Propagat. AP-26, No. 3, 439-447 (May 1978).

[9] Kanda, M., Transients in resistively loaded antennas, and their comparison with conical antennas and TEM horns, International Symposium on Antennas and Propagation, Digest, 13-16, Univ. of Maryland, MD (May 1978).

[10] Kanda, M., Transients in resistively loaded antennas and their comparison with conical antennas and TEM horns, MBSIR 78-876, National Bureau of Standards, Boulder, CO (March 1978).

[11] Wiener, N., Nonlinear Problems in Random Theory (Cambridge, MA, MIT Press, 1959).

[12.] Sarkar, T. K., and Weiner, D. D., Scattering analysis of nonlinearly loaded antennas, IEEE Trans. on Antennas Propagat. AP-24, No. 2, 125-131 (llarch 1976). 
[13] Lin, T. K., and Tesche, F. M., Analysis of antennas and scatterers with nonlinear loads, IEEE Trans. on Antennas Propagat. A.P-24, No. 2, 131-139 (March 1976).

[14] Kanda, M., Analytical and numerical techniques for analyzing an electrically short dipole with a nonlinear load, NBSIR 78-898, National Bureau of Standards, Boulder, CO (Nov. 1978).

[15] Harrington, R. E., Field Computation by Moment Methods (New York: The MacMillan Company, 1968).

[16] Calahan, D. A., Computer-Aided Metwork Design (McCiraw-Hi11, Inc., New York, 1972). 

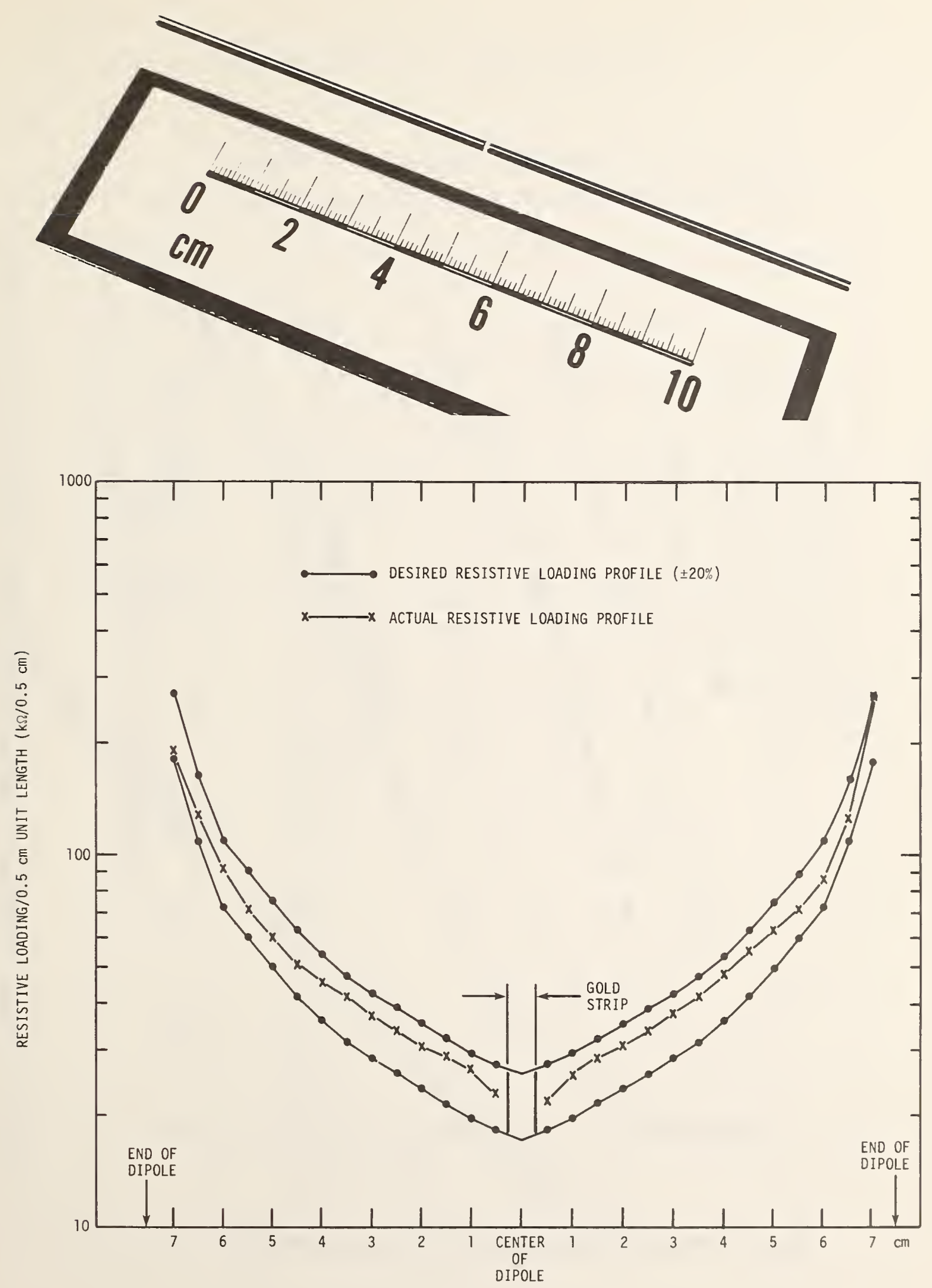

Fig. 1. A traveling-wave linear antenna and its resistive-loading profile. 


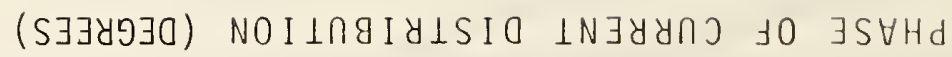

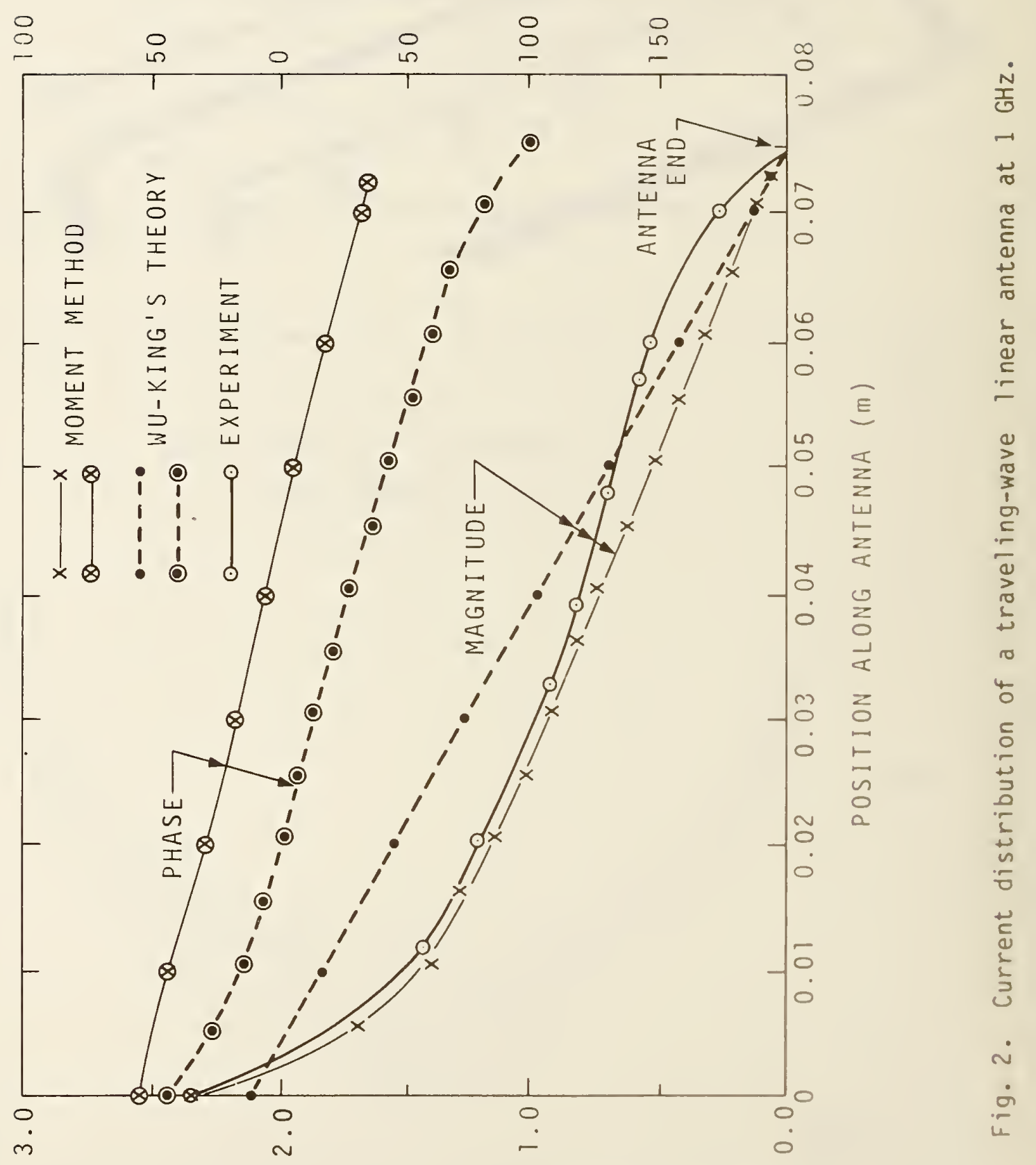

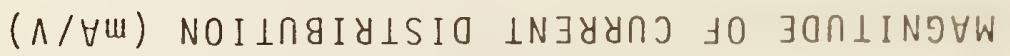


(แ) $H \perp 9 N \exists\urcorner \quad \exists \wedge I \perp \supset \exists \unlhd \unlhd \exists \quad \dashv 0 \quad \perp \forall \forall d \quad \wedge \forall \forall N I 9 \forall W I$

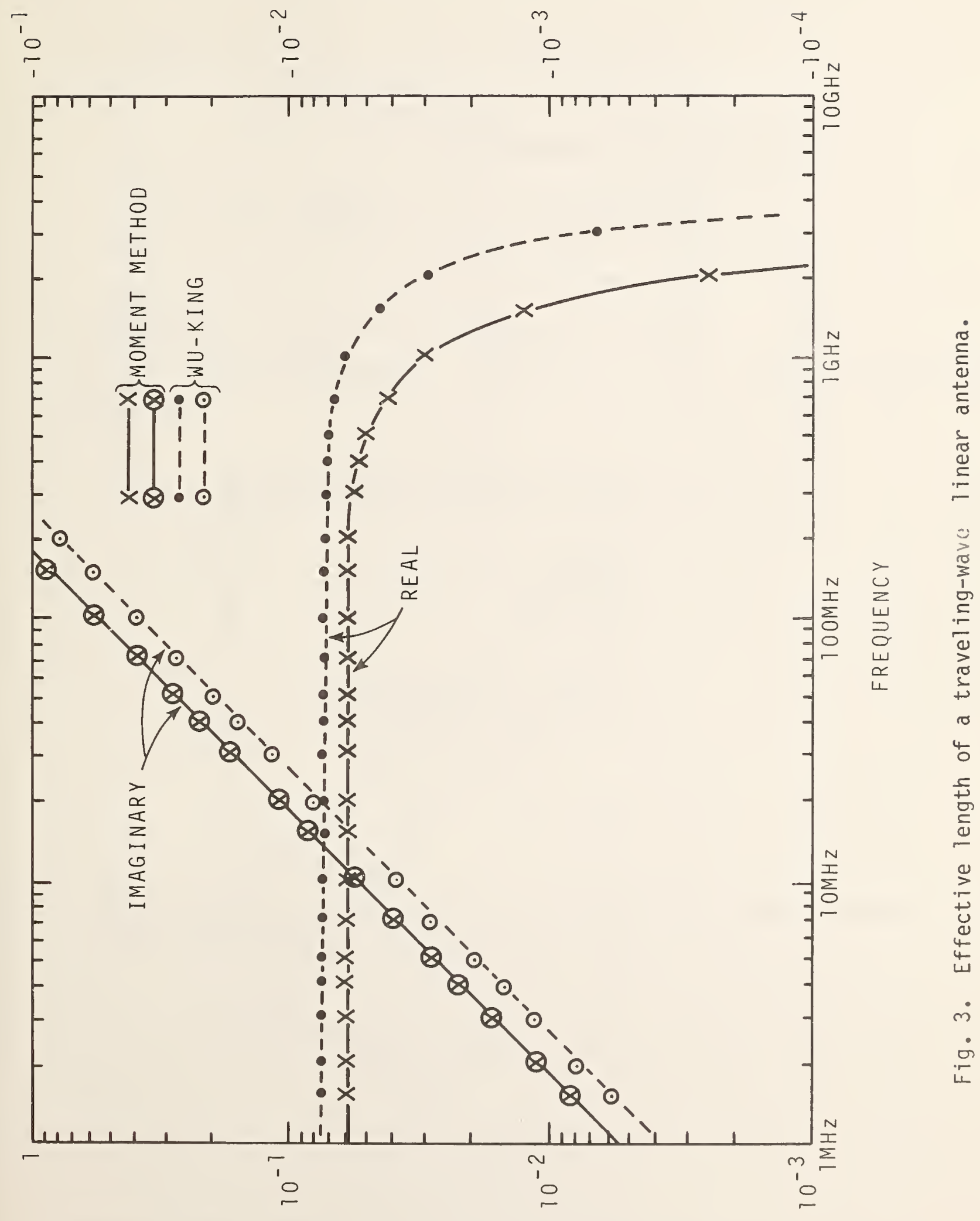

(u) $H \perp 9 N \exists\urcorner \quad \exists \wedge I \perp J \exists \unlhd \unlhd \exists \quad\lrcorner 0 \quad \perp \forall \forall d \quad 7 \forall \exists y$ 

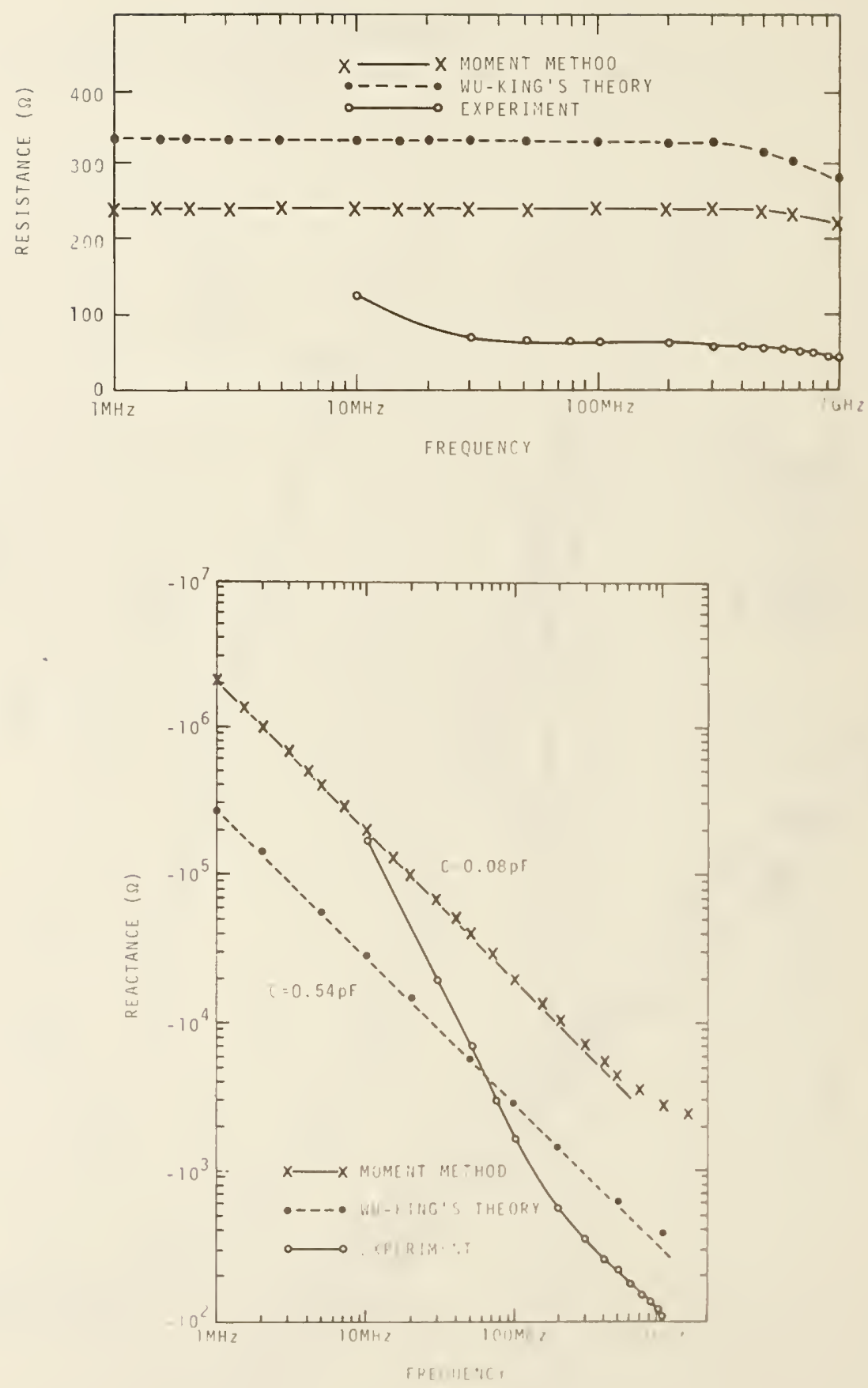

Fig. 4. Driving-point impedance of the traveling-wave linear antenna. 


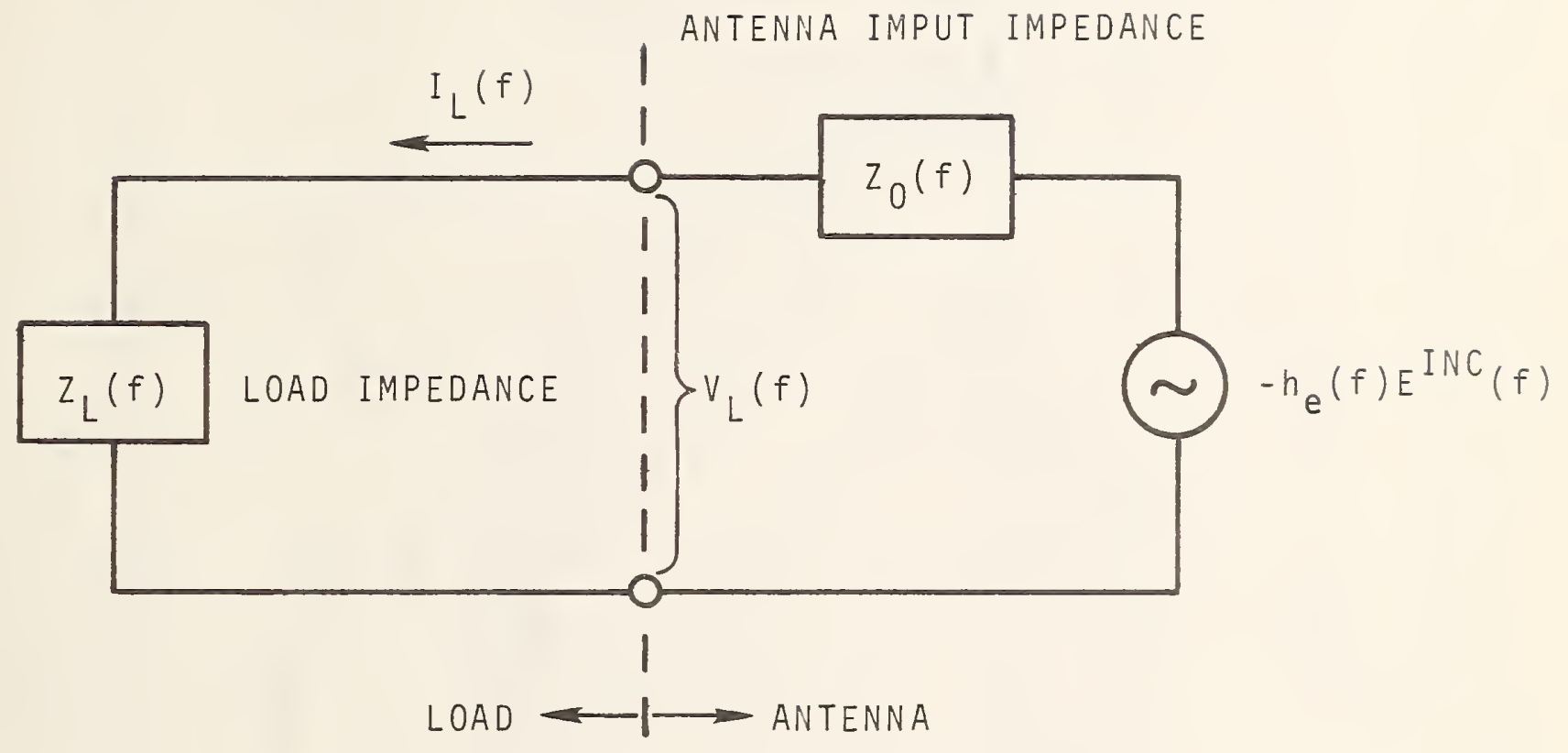

$V_{L}(f)=\frac{-h_{e}(f) E^{I N C}(f) z_{L}(f)}{Z_{0}(f)+z_{L}(f)}$

Fig. 5. Thevenin's equivalent circuit for a traveling-wave linear antenna with a linear load. 


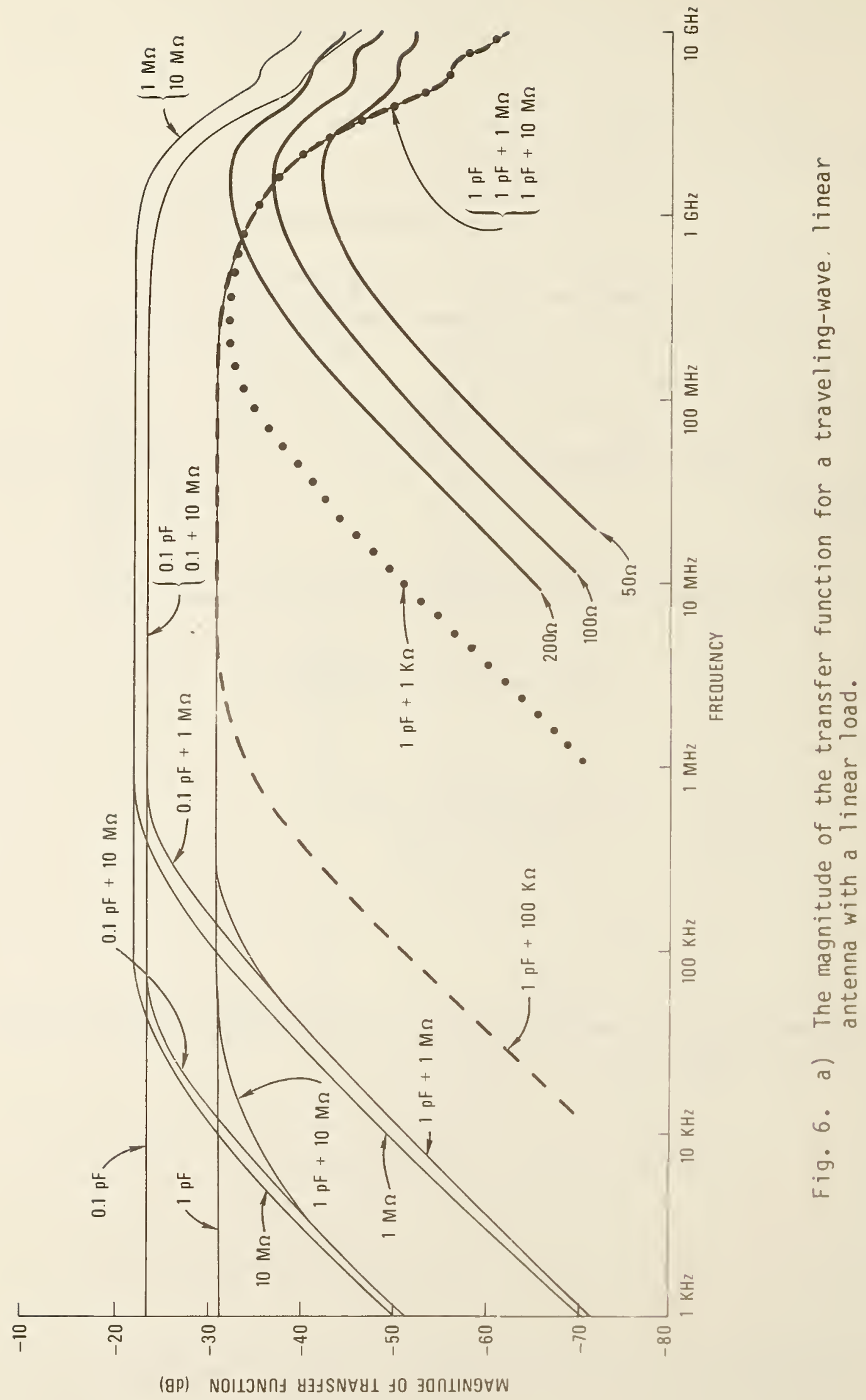




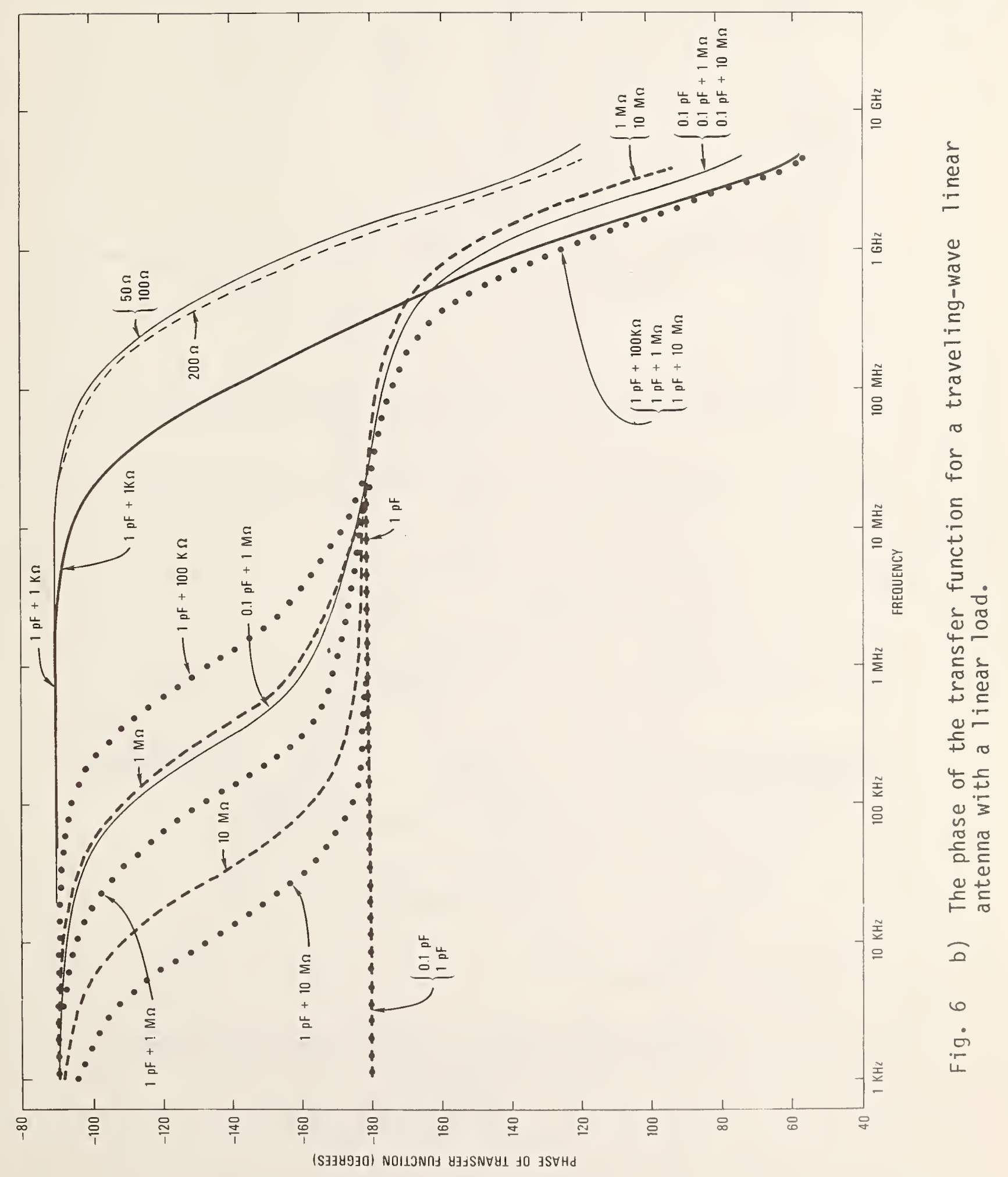



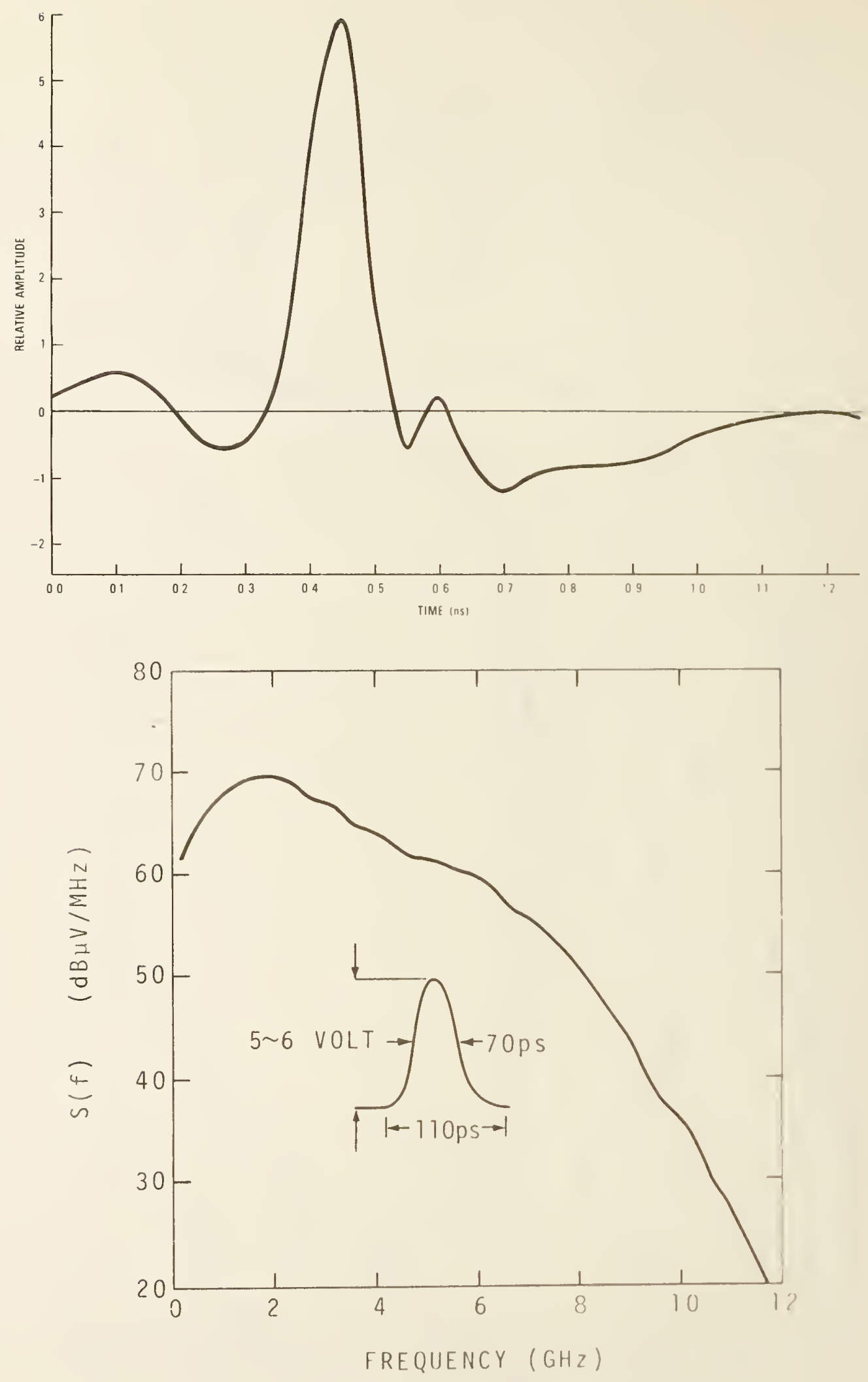

Fig. 7. Time-domain waveform and amplitude spectra of 100-ps EM impulse. 


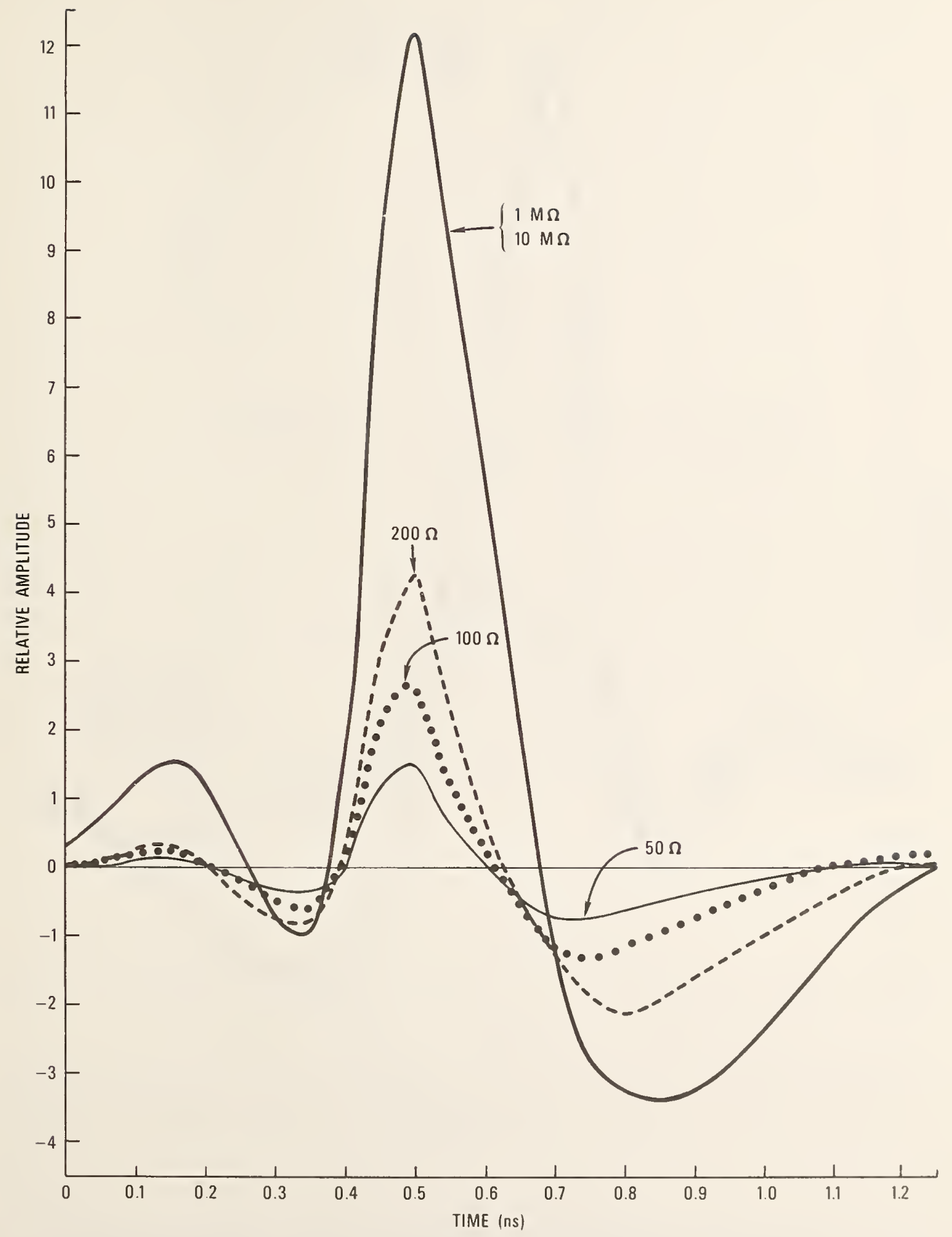

Fig. 8. a) Transient responses of a traveling-wave linear antenna with 100-ps EM impulse with various resistance loads. 


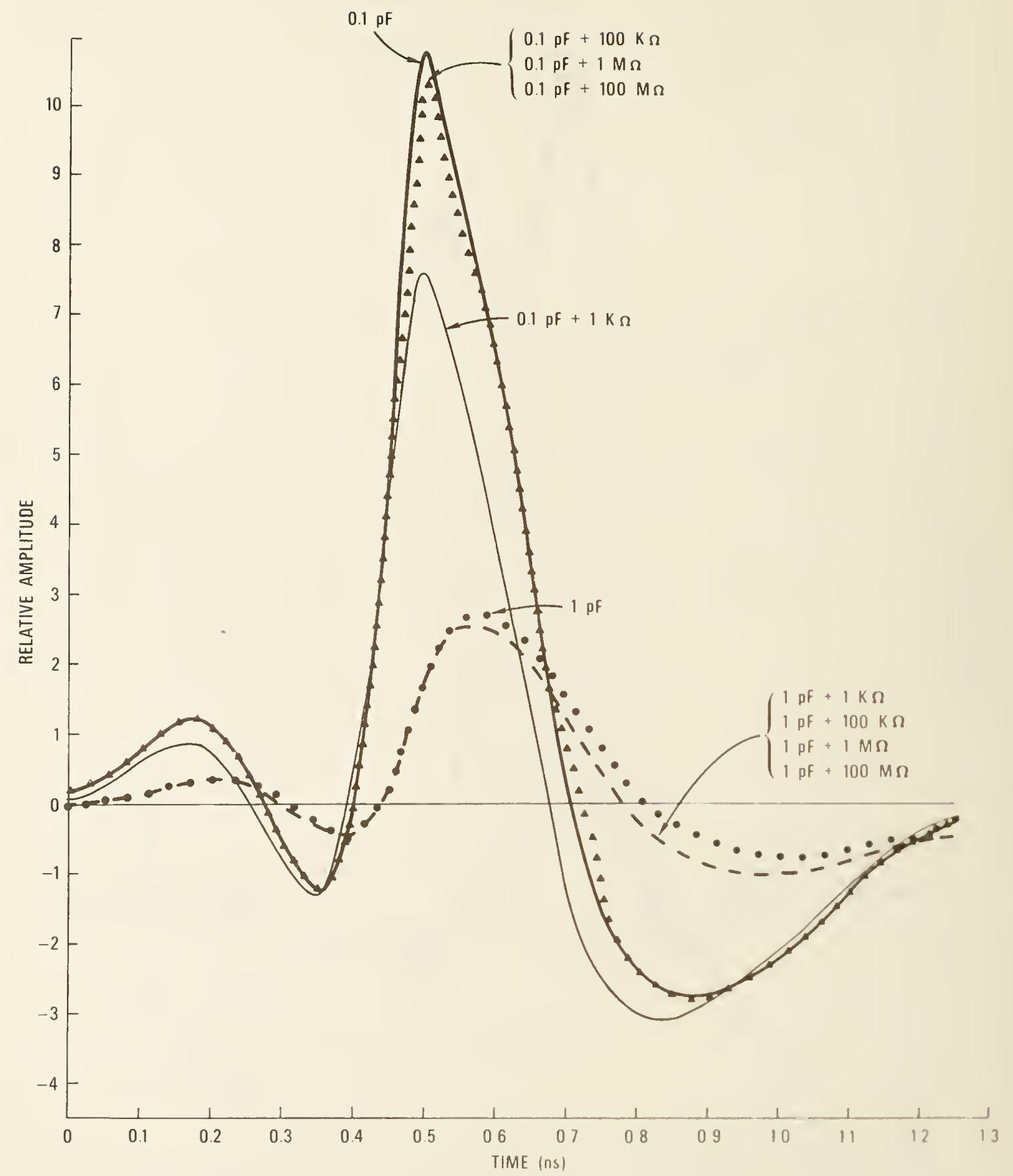

Fig. 8 b) Transient responses of a traveling-wave linear antenna with 100-ps EM impulse with various capacitance loads and capacitanceresistance, parallel combination loads. 

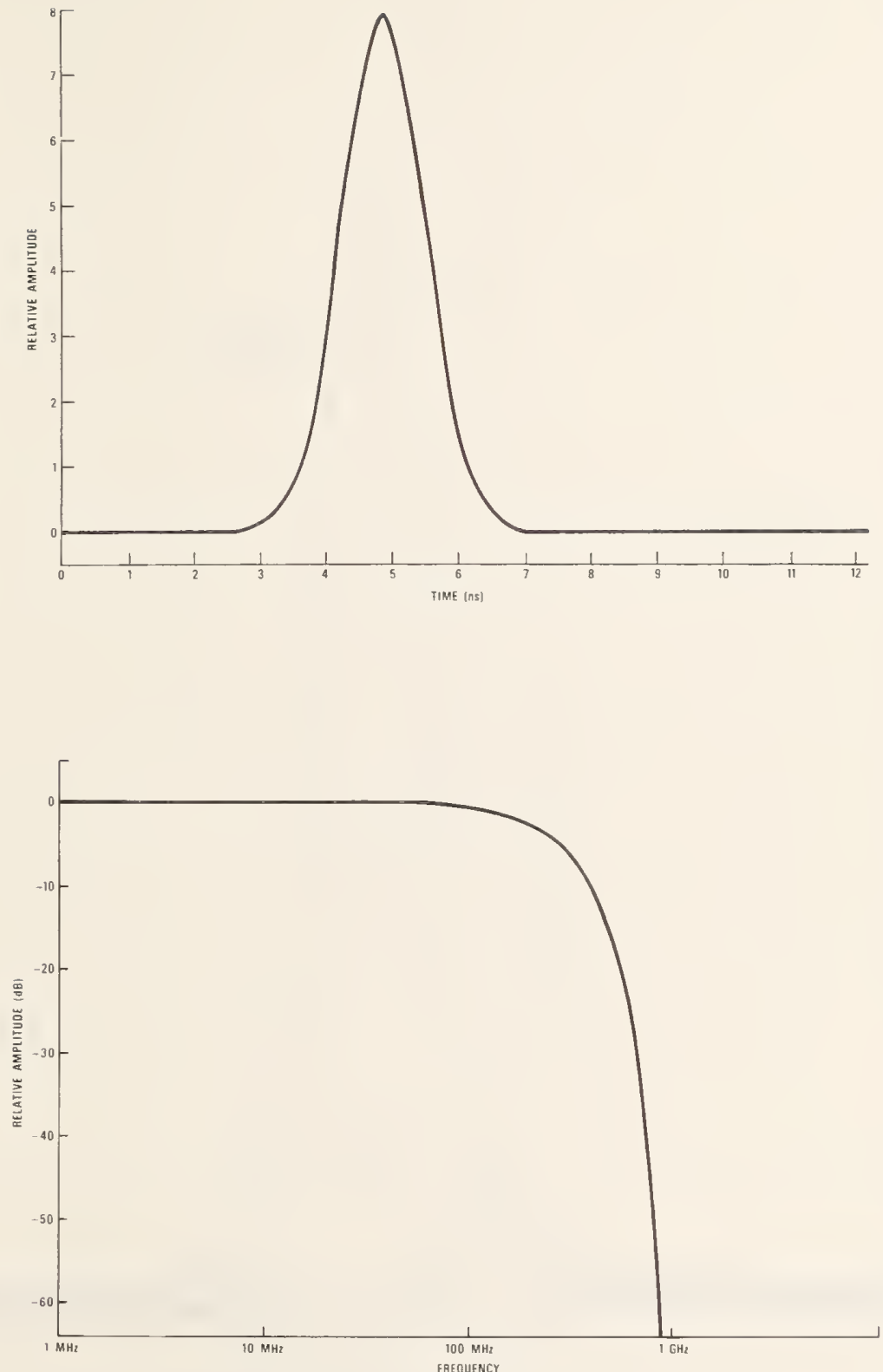

Fig. 9. Time-domain waveform and amplitude spectra of a 1.5-ns Gaussian EM impulse. 


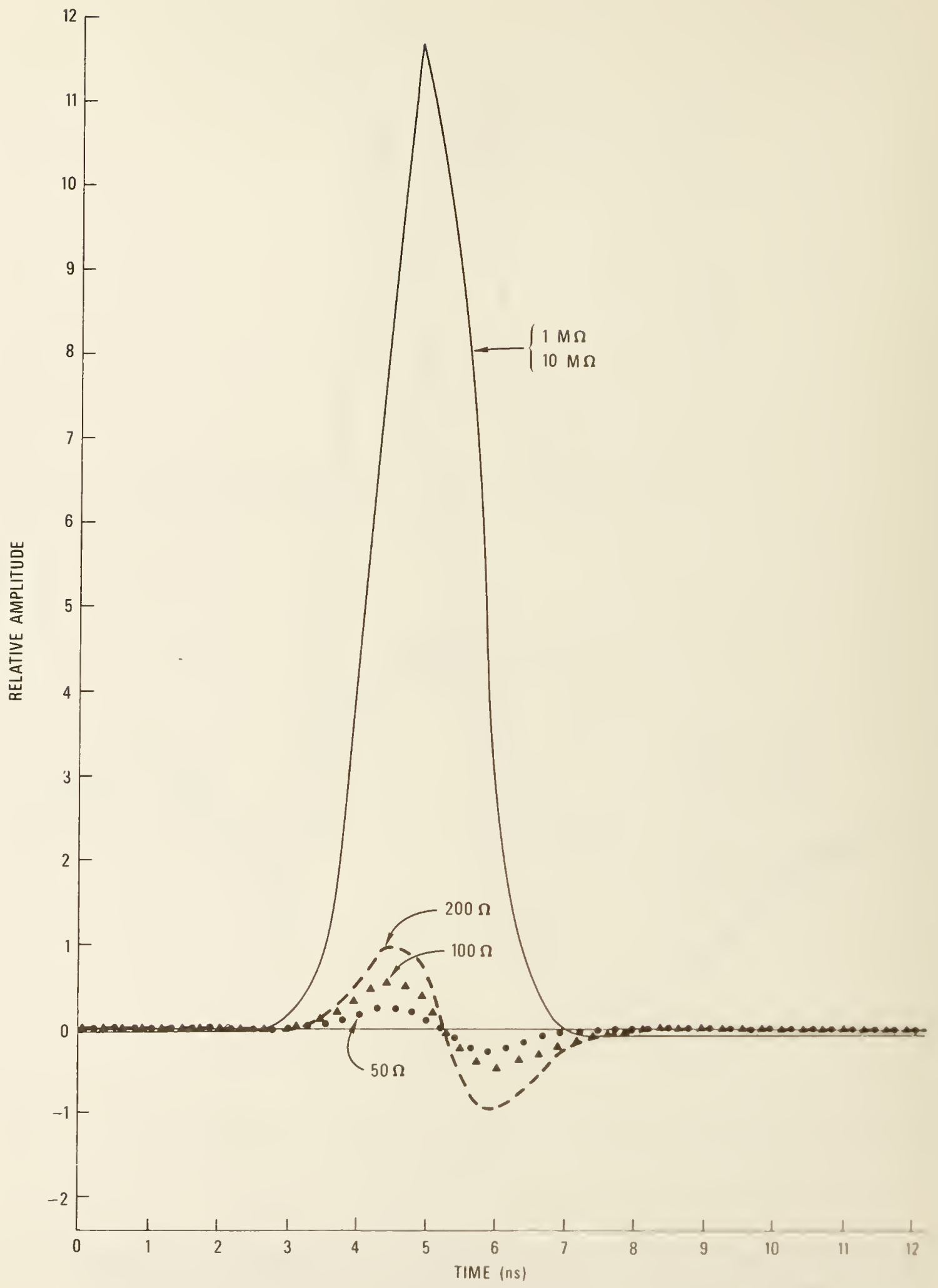

Fig. 10. a) Transient responses of a traveling-wave linear antenna with a 1.5-ns Gaussian EH impulse for various resistance loads. 


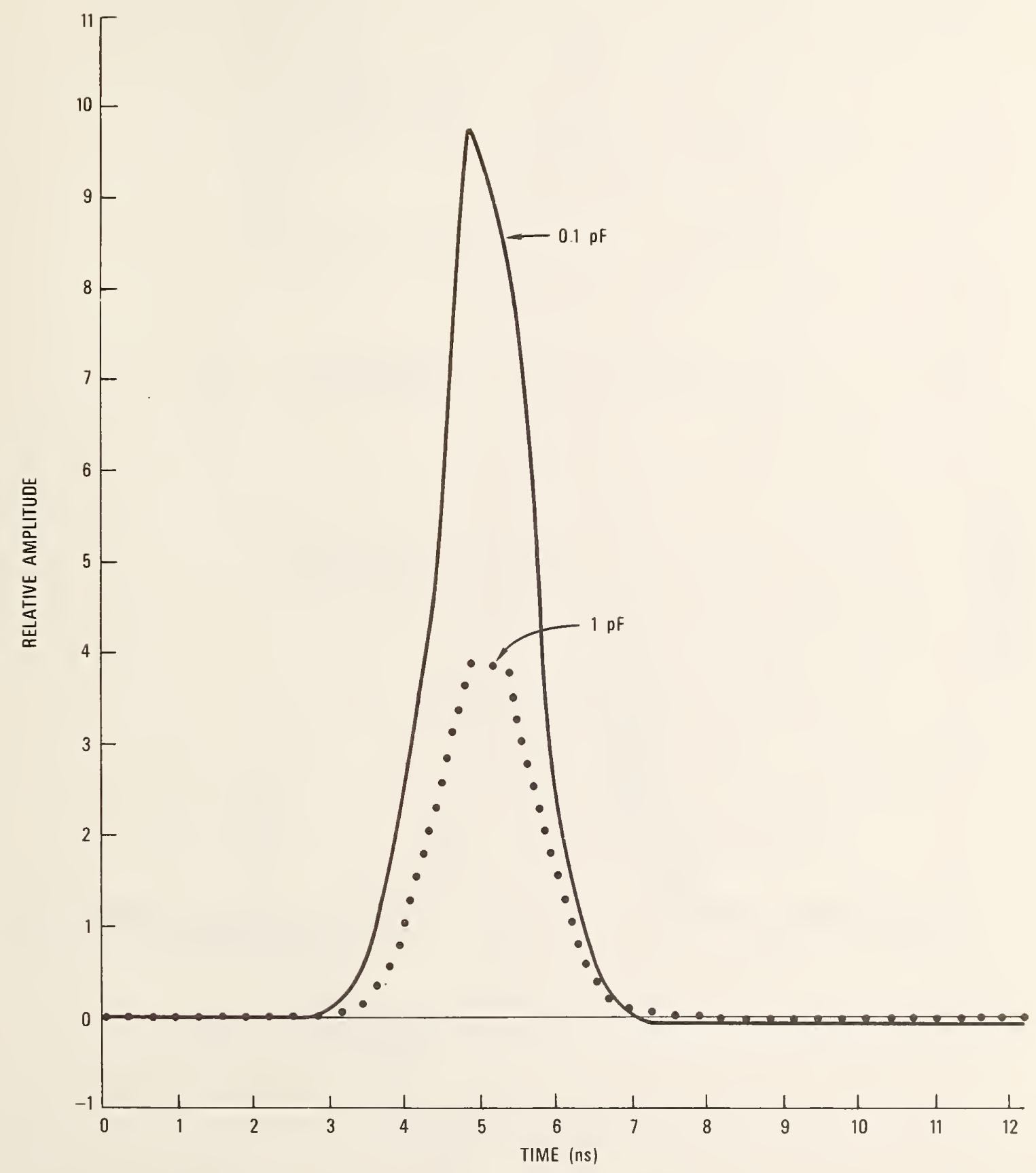

Fig. 10. b) Transient responses of a traveling-wave linear antenna with a $1.5-n s$ Gaussian EM impulse for various capacitance loads. 


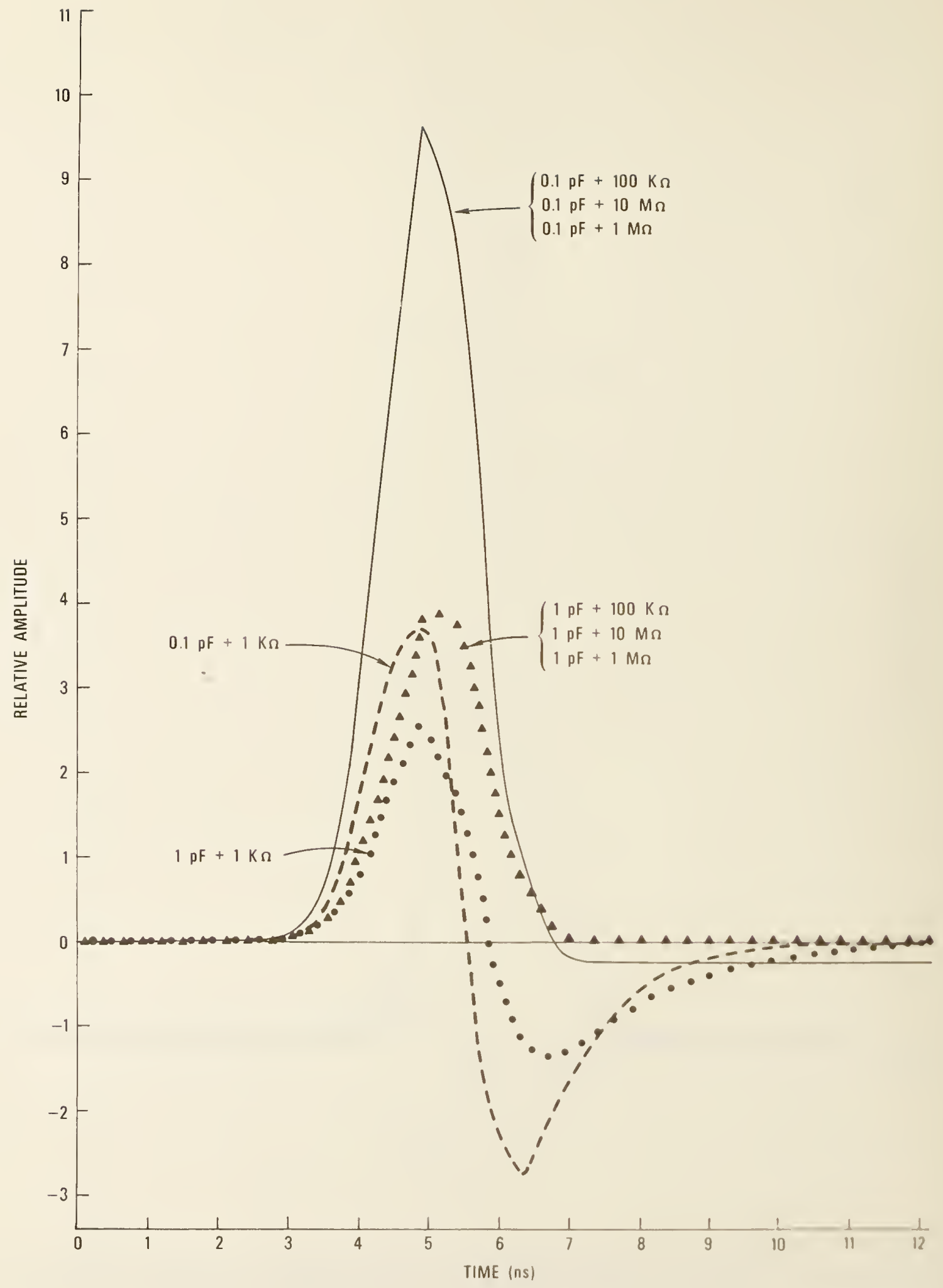

Fig. 10. c) Transient responses of a traveling-wave linear antenna with a 1.5-ns Gaussian EM impulse for various capacitance-resistance, parallel combination loads. 


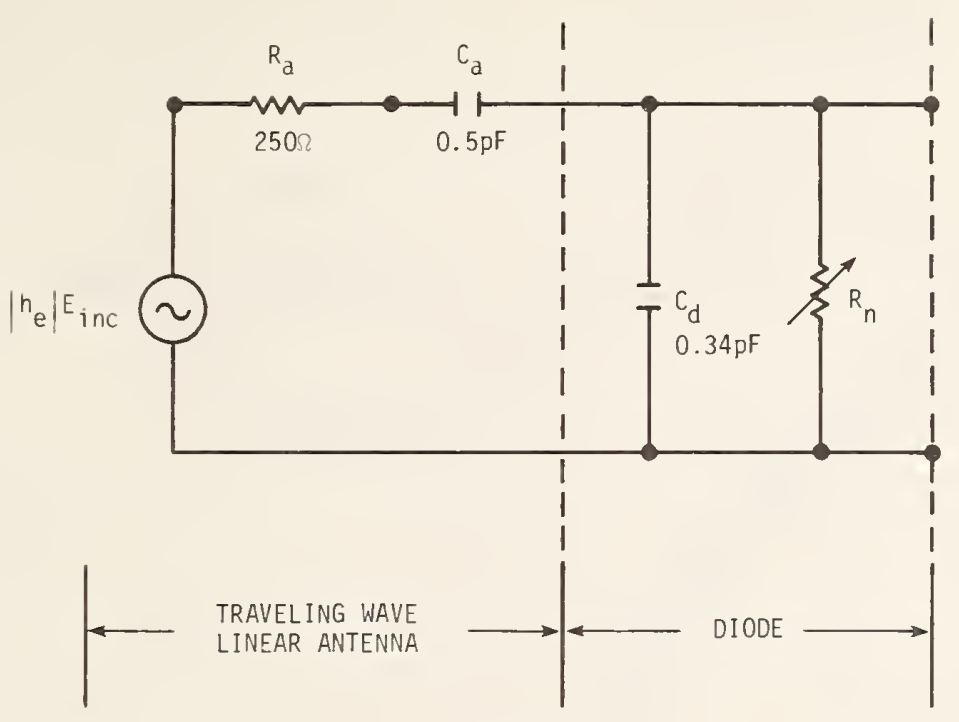

MODEL I

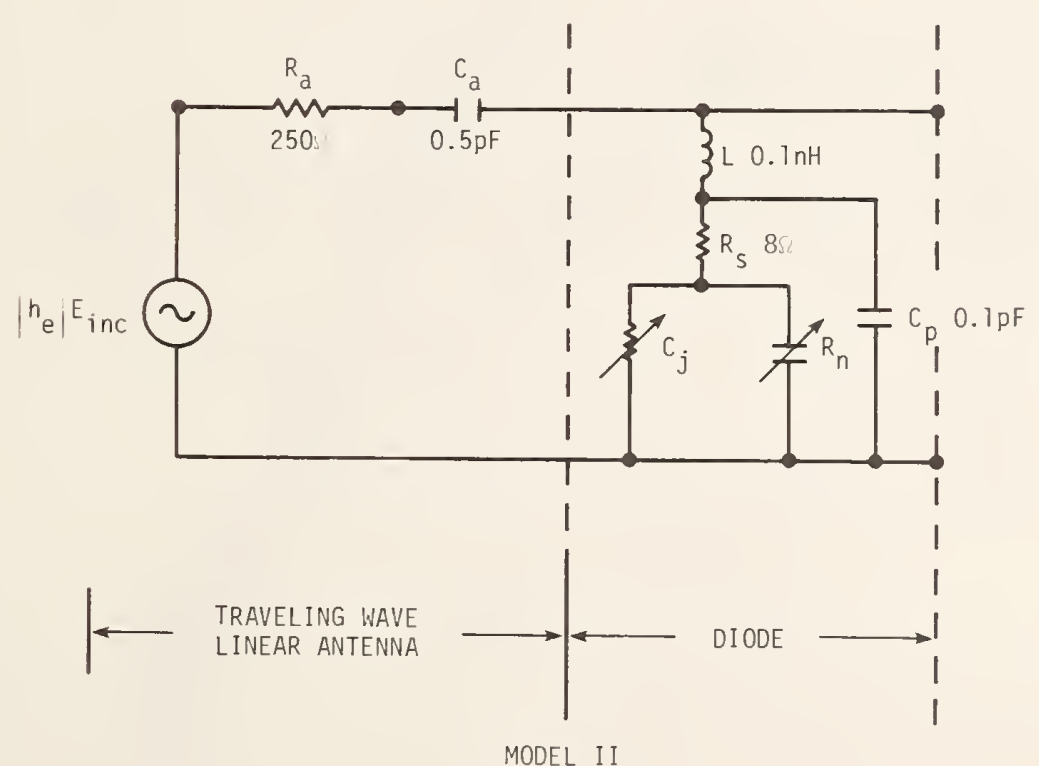

Fig. 11. Thevenin's equivalent circuit for a traveling-wave linear antenna with a nonlinear load. 

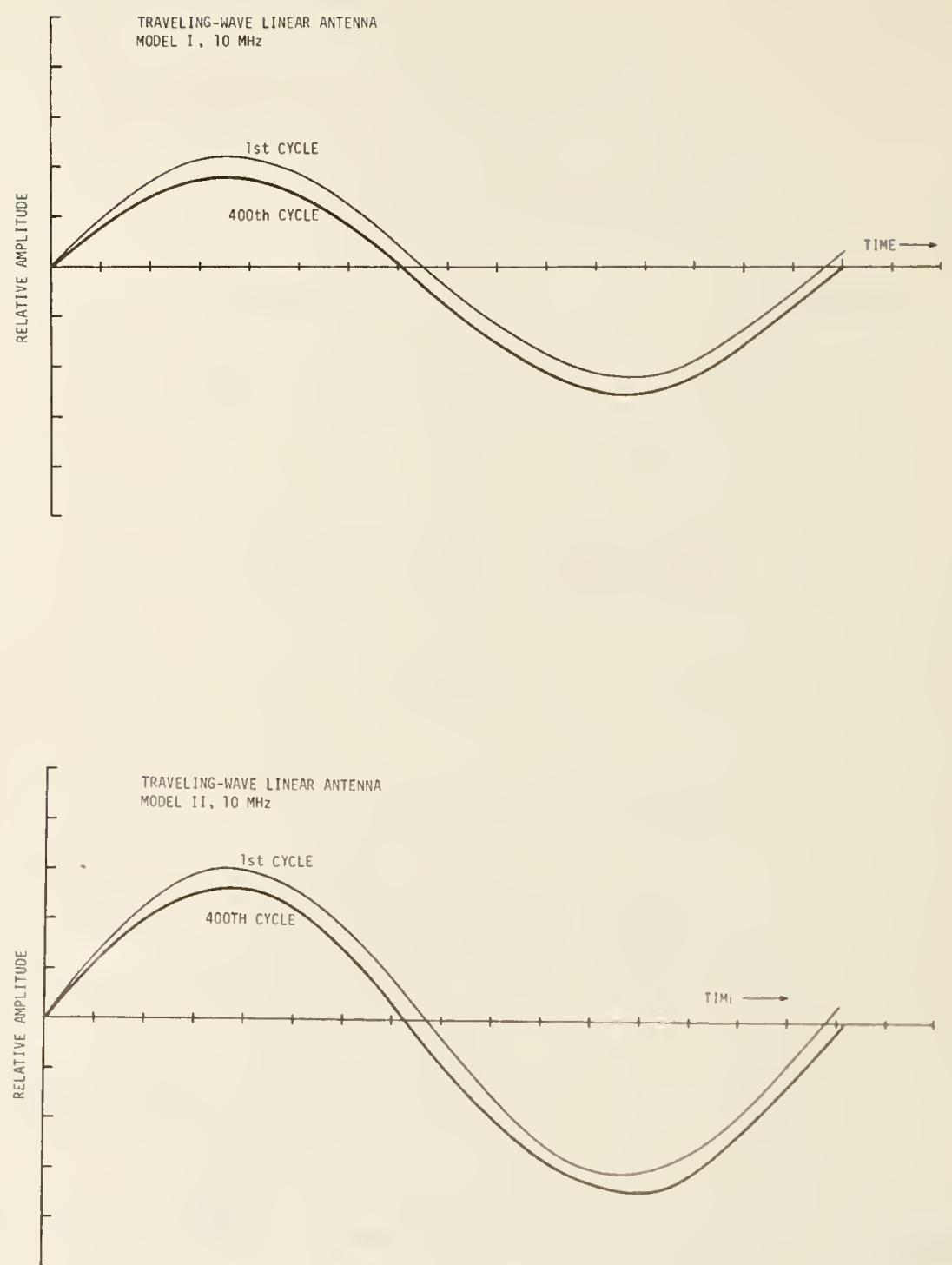

Fig. 12. Detected EM sinusoidal waves by a traveling-wave linear antenna with a nonlinear load. 


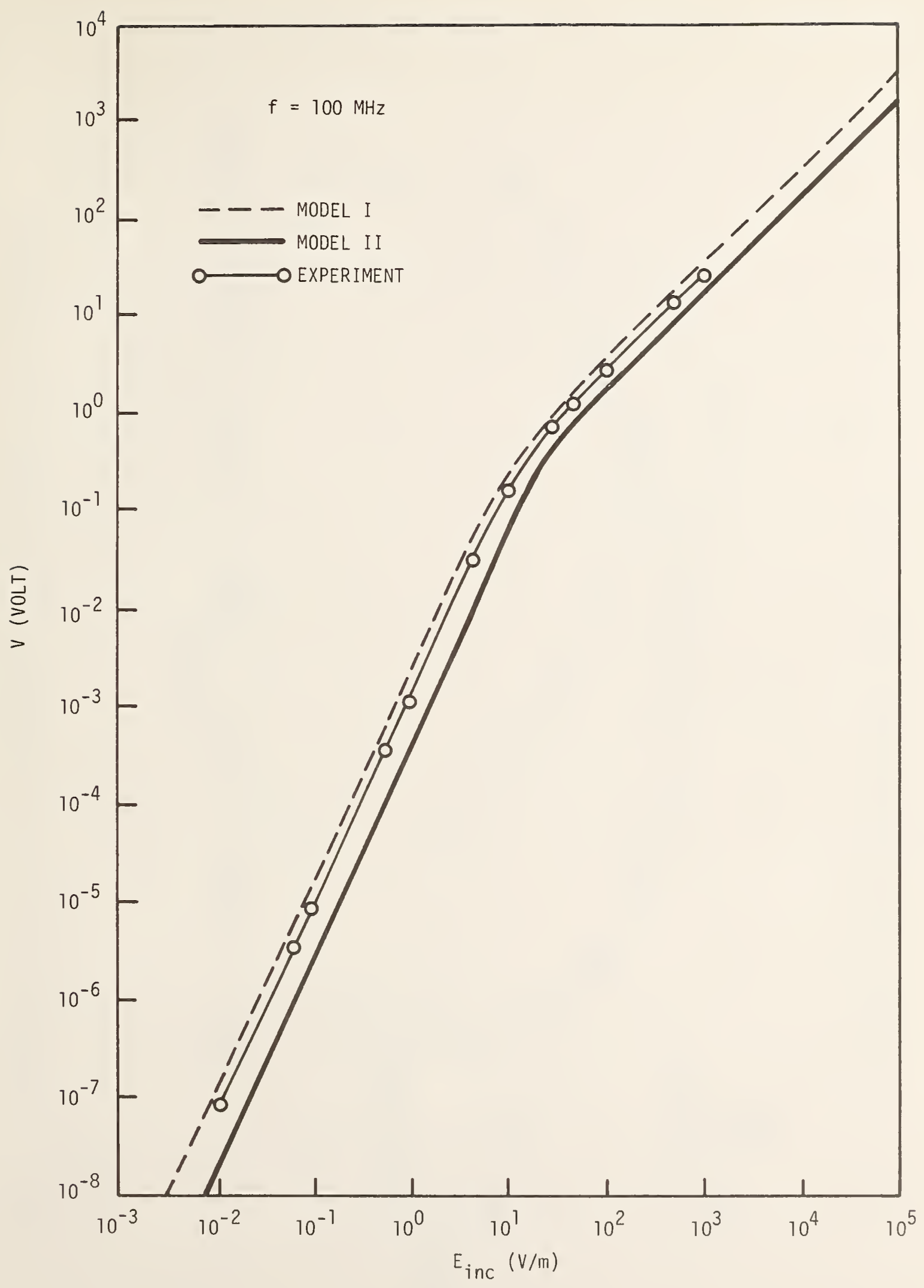

Fig. 13. Dynamic range of a traveling-wave linear antenna with a nonlinear load. 


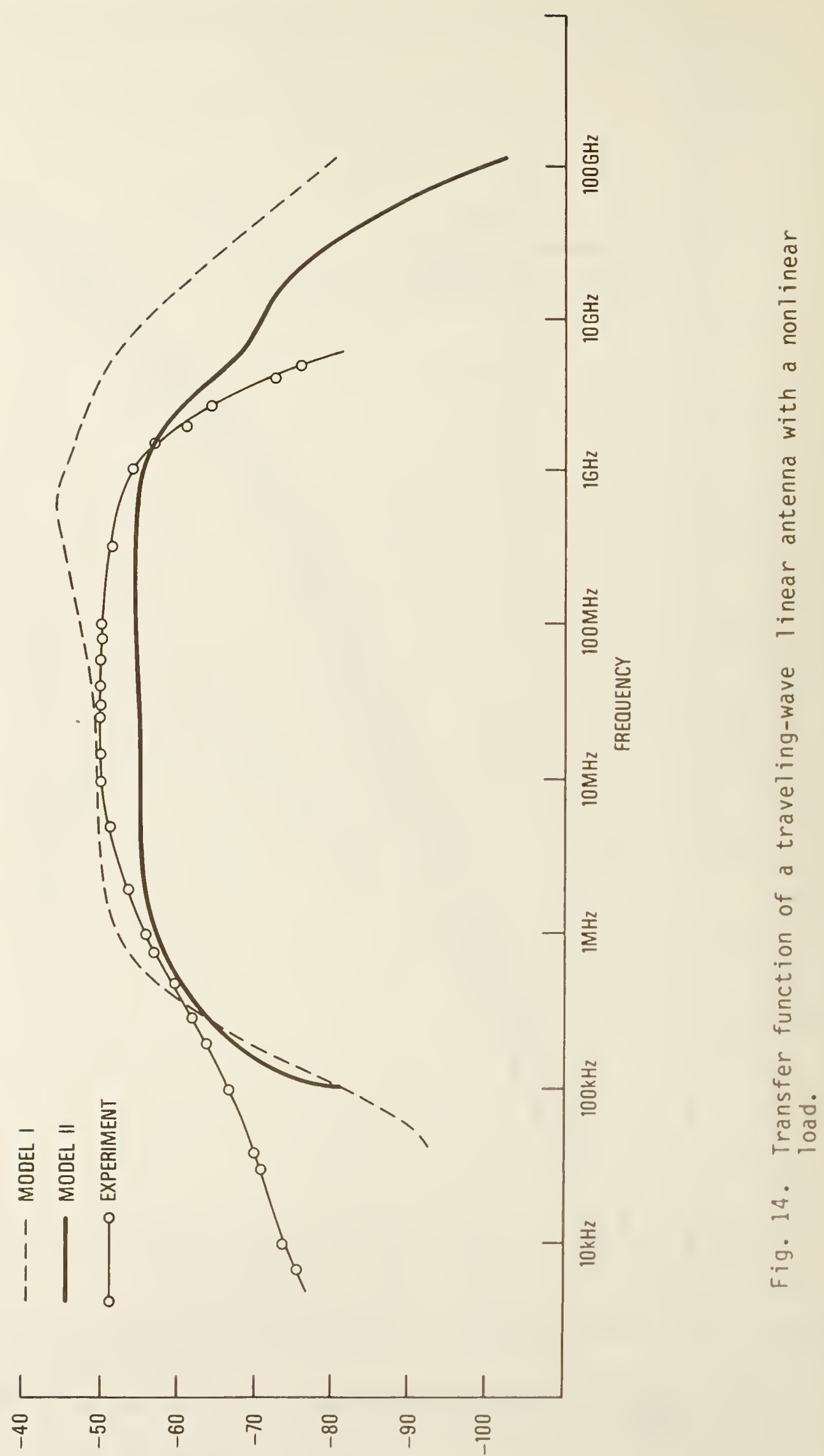

(gP) NOILJNก 


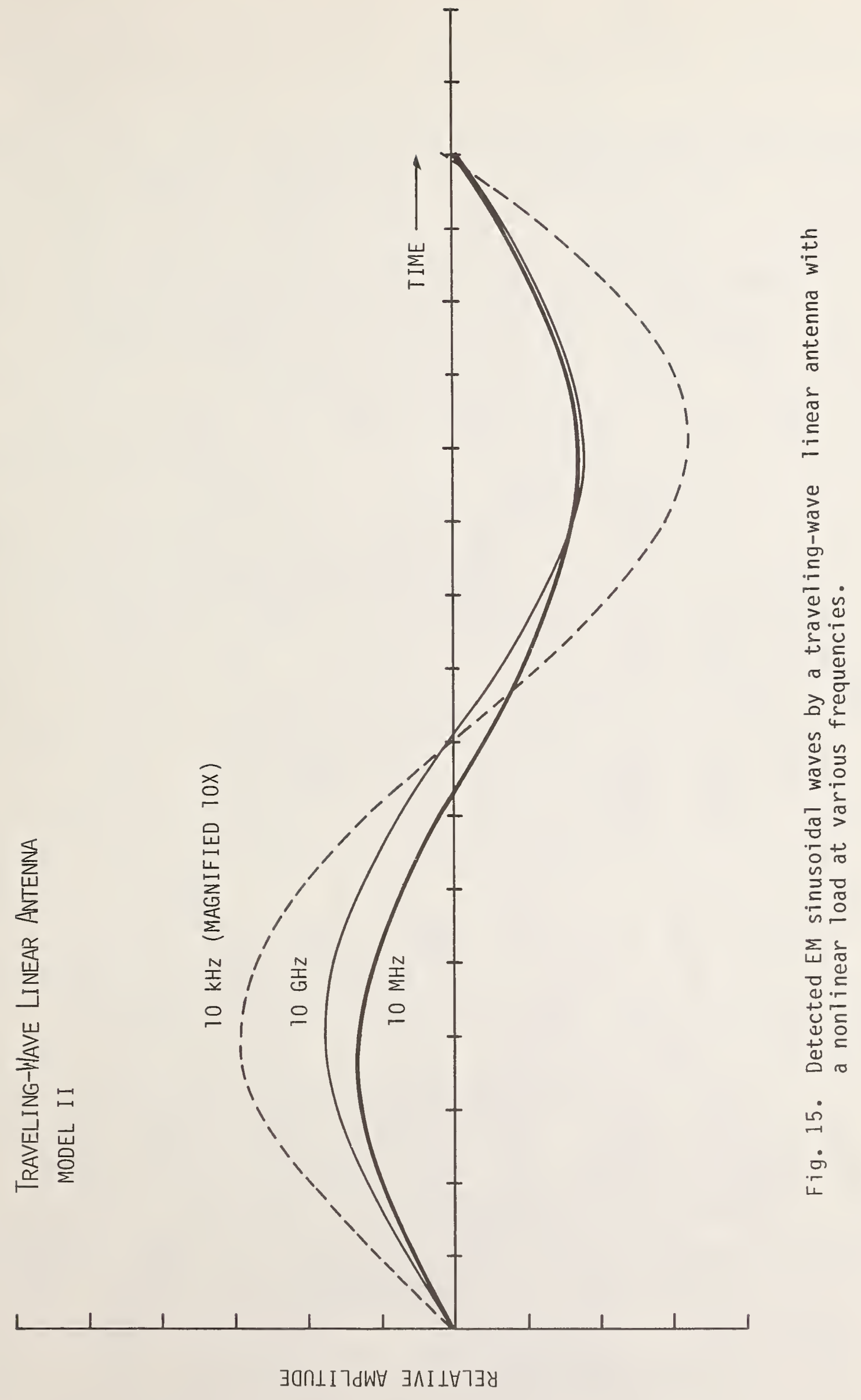




\begin{tabular}{|c|c|c|c|}
\hline $\begin{array}{l}\text { U.S. DEPT. OF COMM. } \\
\text { BIBLIOGRAPHIC DATA } \\
\text { SHEET }\end{array}$ & $\begin{array}{l}\text { 1. PUBLICATION OR REPORT NO. } \\
\text { NBSIR 78-892 }\end{array}$ & $\begin{array}{l}\text { 2. Gov't Accession } \\
\text { No. }\end{array}$ & 3. Recipient's Accession No. \\
\hline \multirow{2}{*}{\multicolumn{3}{|c|}{$\begin{array}{l}\text { 4. TITLE AND SUBTITLE } \\
\text { THE TIME DOMAIN CHARACTERISTICS OF A TRAVELING- } \\
\text { WAVE LINEAR ANTENNA WITH LINEAR AND NONLINEAR LOADS }\end{array}$}} & $\begin{array}{l}\text { 5. Publication Date } \\
\text { February } 1979\end{array}$ \\
\hline & & & $\begin{array}{l}\text { 6. Performing Organization Code } \\
723.03\end{array}$ \\
\hline & 8. Performing Organ. Repore No. \\
\hline \multirow{2}{*}{\multicolumn{3}{|c|}{$\begin{array}{l}\text { 9. PERFORMING ORGANIZATION NAME AND ADDRESS } \\
\text { NATIONAL BUREAU OF STANDARDS } \\
\text { DEPARTMENT OF COMMERCE } \\
\text { WASHINGTON, D.C. } 20234\end{array}$}} & $\begin{array}{l}\text { 10. Project/Task/Work Unit No. } \\
7233281\end{array}$ \\
\hline & & & 11. Contrace/Grane No. \\
\hline \multirow{2}{*}{\multicolumn{3}{|c|}{ 12. Sponsoring Organization Name and Complete Address (Street, City, State, ZIP) }} & $\begin{array}{l}\text { 13. Type of Keports Period } \\
\text { Covered }\end{array}$ \\
\hline & & & 14. Sponsuring Agency Code \\
\hline
\end{tabular}

15. SUPPLEMENTARY NOTES

16. ABSTRACT (A 200-word or less factual summary of most significant information. Il document includes a signilicant bibliography or literature survey, mention it here.)

This paper discusses the time-domain characteristics of a traveling-wave linear antenna with linear and nonlinear loads. The fast Fourier transform (FFT) is used to analyze an antenna with a linear load. A numerical time-stepping, finite-difference equation method is used to analyze an antenna with a nonlinear load. The nonlinear effect is treated by the Newton-Raphson iteration technique. Effects of varlous linear and nonlinear loads are examined. Physical 1nsight into the nonlinear loading of the antenna is also given in terms of detected time-domain sinusoldal electromagnetic (EM) waves.

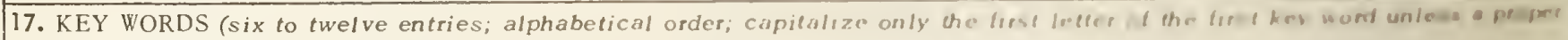
name; separated by semicolons)

Fast Fourier transform; Newton-Raphson iteration method: linear

load; nonlinear load; time-domain measurements; time-stepping

finite-difference technique; transient; traveling-wave antemm.

18. AVAILABILITY $\quad$ Unlimited

For Official Distribution. Do Not Release to NTIS

Order From Sup. of Doc., U.S. Government Psinting Uffuce

Washington, D.C. 20402, SD Stock No. Sivo03-00?

\begin{tabular}{|c|c|}
\hline $\begin{array}{l}\text { 19. Y(UKIT CLAS } \\
\text { IIIISKLPUKT) }\end{array}$ & 21. N0. (1) 124.1 \\
\hline I $N($ I Ass II II & \\
\hline $\begin{array}{l}\text { 20. SL( IRII) CLASS } \\
\text { THIS PACE) }\end{array}$ & 22. linese \\
\hline $1 / 1 \mid 10-11 \| 1 \mathrm{H}$ & \\
\hline
\end{tabular}

